\title{
Human preferences for time-dependent and response-dependent reinforcement schedules
}

\author{
ROBERT W. SCHAEFFER \\ Auburn University, Auburn, Alabama 36830
}

\begin{abstract}
Human preferences for various fixed-ratio schedules were compared with a fixed-interval 30 -sec schedule in 56 male and female subjects. Using counter points as reinforcers and a preference paradigm permitting interspecies comparisons, three experiments yielded data suggesting that schedule preferences reflect sensitivities to time-dependent and responsedependent variables, rate of reinforcement parameters, and the total number of responses emitted by the organism, in that order of importance. The importance of this technology for tests of Premack's reinforcement principle and ascertainment of the positive or negative valence of reinforcement schedules is briefly discussed.
\end{abstract}

In several previous reports, I and several former graduate students have reported that pigeons and raccoons prefer time-dependent over response-dependent reinforcement schedules (King, Schaeffer, \& Pierson, 1974; Schaeffer, 1979). Unpublished data from my laboratory indicate the same preference holds for albino rats and gerbils. Preferences for time-dependent over response-dependent schedules are obtained even when reinforcement rate on the latter equals or slightly exceeds that of the former (Schaeffer, 1979). Preferences for time-dependent over response-dependent schedules are reversible when reinforcement rate on the response-dependent schedule is more than twice reinforcement rate on the time-dependent schedule, and total responses emitted influence preference, but neither factor alone can account for schedule preference (Schaeffer, 1979). I have suggested that schedule preferences reflect organismic reactivities to (1) timedependent vs. response-dependent variables to which the organism is sensitive, (2) rate of reinforcement parameters, and (3) the total response requirement placed upon the organism, in that order of importance (Schaeffer, 1979). These variables were tested in humans in the experiments described below in another demonstration of a preference methodology that can be successfully applied to all organisms, independently of species affiliation (cf. Schaeffer, 1979).

\section{GENERAL METHOD}

\section{Subjects}

Twenty-eight female and 27 male sophomores from introductory honors psychology classes taught by the author at Florida

This research was supported in part by Public Health Service Research Grants MH-08755 and MH-12025, Robert W. Schaeffer, principal investigator. These data were collected in collaboration with two former graduate students, G. D. King and S. C. Pierson, and were presented at the Nineteenth Annual Meeting of the Psychonomic Society in San Antonio, Texas, November 1978.
State University served as subjects. Participation was completely voluntary, without remuneration or course credit. Subjects were first separated by sex, then randomly assigned to one of the six groups in the three experiments described below. Experiment 1 employed 11 females and 10 males; Experiment 2 employed 13 females and 13 males; Experiment 3 employed 4 females and 4 males. Experiments 1, 2, and 3 were run separately and consecutively, in the order named. The same apparatus was used in all experiments. The specific procedures in each experiment differed slightly, as explained below, but all experiments were conducted within the purview of the general procedure described below.

\section{Apparatus}

Each subject was seated individually in a small room at a table on which was placed a human response console instrumented upon a standard gray metal Bud C-1893 cabinet. On the console were four indicator lights, four Micro-Switch IAT2 response levers, and four Sodeco Model TCeF5E electrical reset digital counters. The lights, counters, and levers formed four vertical columns, $8.89 \mathrm{~cm}$ apart, with the lights located $1.27 \mathrm{~cm}$ above the tops of the respective counters, and with the levers located $.64 \mathrm{~cm}$ below the bottom of the respective counters. Programming equipment was remoted by cable and located in a separate room. Programming, reinforcement deliveries (points), and recording of all responses were automatically sensed and routed by standard electromechanical circuitry.

\section{General Procedure}

Subjects were given an opportunity to earn points by responding on either a fixed-interval (FI) schedule or a fixedratio (FR) schedule. In all phases of each experiment, only the two levers, two counters, and two cue lights on the left half of the console were functional. The FI schedule was programmed on the lever to the subject's right; the FR schedule was programmed on the lever to the subject's left. The cue light was used as an $\mathbf{S}^{\mathbf{D}}$ to signal schedule availability on the lever directly below the cue light.

Each experiment consisted of two basic phases for each subject, a training phase and a choice phase. At the beginning of each experiment, instructions were read to the subject that explained how the apparatus functioned, described the difference between FI and FR schedules, informed the subject that the experimenter was interested in which of the schedules students preferred, and informed the subjects their performance would be compared with that of pigeons.

During the training phase preceding preference testing in each experiment, only one reinforcement schedule was operative 
at any given time. The subject was required to earn five consecutive reinforcements on the available schedule, then five consecutive reinforcements on the other schedule. Each reinforcement consisted of the registering of a total of eight points in approximately $.75 \mathrm{sec}$ on the counter associated with the respective lever. In each experiment, half of the subjects of each sex were trained first on the FR schedule, and the other half were trained first on the FI schedule. Following training on both the FI and FR schedules, the counters were reset to zero, the experimenter left the room, and the choice phase was begun.

In the choice phase, both schedules of reinforcement were made concurrently operative and freely available for each subject to choose between them. However, the first response on either lever rendered the other lever inoperative and extinguished the nonpreferred lever cue light for a period of $2 \mathrm{~min}$. During this 2-min period, reinforcements could be obtained only on the lever initially chosen; responses to the other lever produced no programmed consequences. At the end of each 2-min period, the formerly preferred lever was made inoperative, its cue light was extinguished, and the subject was required to wait $10 \mathrm{sec}$, after which both cue lights were illuminated, thereby signaling to the subject that another choice period between the levers was available. This sequence of events, a choice period followed by a 2 -min response period, followed by a 10 -sec time-out (TO), was continued throughout all choice periods in Experiments 1 and 2 until each subject earned a total of 5.0 reinforcement deliveries, for a grand total of 400 points possible on the two counters. After the subject received his last reinforcement, the experimenter reentered the room and thanked and dismissed the subject.

\section{EXPERIMENT 1}

\section{Procedure}

Subjects could earn points by responding on either a FI 30 -sec or a FR 120 schedule. The FI 30 -sec requirement was chosen because it was the same value used in preference experiments employing pigeons (Schaeffer, 1979) and raccoons (King et al., 1974). The FR 120 requirement was based on pilot data from five male and five female subjects that showed that on FR schedules both sexes emitted approximately 120 leverpresses each $30 \mathrm{sec}$ on the apparatus, thereby assuring that rate of reinforcement on the FR schedule could not substantially exceed rate of reinforcement on the FI 30-sec schedule. The data of concern were preference, as reflected by a schedule choice, rate of reinforcement earned on each schedule, percent of total reinforcements earned on each schedule, and rate of responding on each schedule.

\section{Results and Discussion}

The first two columns in Table 1 summarize the data from Experiment 1. Data were obtained originally from 10 males and 11 females, but data from 2 males and 1 female are not included because of obvious experimenter errors in data compilation. There was a clear preference by both sexes for the FI 30-sec schedule. Percent reinforcements earned on each schedule closely paralleled percent entry choices for each schedule. The former was the result, rather than the cause, of the latter, for reinforcement rate was potentially greater on the FR schedule (as high as 2.5 to 3.0 reinforcements per minute) than on the FI schedule (reinforcement rate was limited to 2.0 per minute). Rate of responding on the FR was substantially greater, as expected, than rate of responding on the FI. Overshooting of the FR requirement (cf. Schaeffer, 1966) was equally probable
Table 1

Mean Values of the Dependent Variables from the Choice Phases of Experiments 1 and 2 for Between-Groups Comparisons of FRs 120, 100, 80, 60, and 40 with the FI 30-sec Schedule

\begin{tabular}{|c|c|c|c|c|c|c|c|c|}
\hline & \multicolumn{6}{|c|}{ Reinforcements } & \multirow{2}{*}{\multicolumn{2}{|c|}{$\begin{array}{c}\text { Response } \\
\text { Rate } \dagger\end{array}$}} \\
\hline & \multicolumn{2}{|c|}{$\begin{array}{l}\text { Schedule } \\
\text { Entries* }\end{array}$} & \multicolumn{2}{|c|}{$\begin{array}{l}\text { Earned Each } \\
\text { Schedule* }\end{array}$} & \multicolumn{2}{|c|}{$\begin{array}{l}\text { Reinforce- } \\
\text { ment Rate } \dagger\end{array}$} & & \\
\hline & $\mathbf{M}$ & $\mathrm{F}$ & $\mathbf{M}$ & 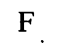 & $\mathbf{M}$ & $\mathrm{F}$ & $\mathbf{M}$ & $\mathrm{F}$ \\
\hline FR 120 & 24 & 16 & 20 & 13 & 1.5 & 1.5 & 125 & 121 \\
\hline FI 30 & 76 & 84 & 80 & 87 & 1.9 & 1.9 & 40 & 50 \\
\hline FR 100 & 36 & 42 & 38 & 44 & 2.4 & 1.9 & 111 & 105 \\
\hline FI 30 & 64 & 68 & 62 & 66 & 1.9 & 1.9 & 30 & 28 \\
\hline FR 80 & 19 & 38 & 18 & 39 & 1.7 & 2.1 & 87 & 81 \\
\hline FI 30 & 81 & 62 & 82 & 61 & 1.7 & 2.0 & 28 & 9 \\
\hline FR 60 & 19 & 65 & 27 & 65 & 3.3 & 3.1 & 61 & 61 \\
\hline FI 30 & 81 & 35 & 73 & 24 & 1.9 & 1.7 & 20 & 52 \\
\hline FR 40 & 84 & 61 & 93 & 75 & 5.2 & 4.0 & 40 & 41 \\
\hline FI 30 & 16 & 39 & 7 & 25 & 1.9 & 1.8 & 74 & 63 \\
\hline
\end{tabular}

Note-M $=$ male, $F=$ female. $\quad$ *Percentages. $\quad$ Rate/minute.

for males and females but did not increase rate of reinforcement on the FR schedule, since (1) responses emitted during reinforcement delivery were ineffective in satisfying the FR requirement for the next reinforcer, and (2) some "excessive" FR responding reflected subjects' failures to earn all reinforcement opportunities potentially available. Stated differently, subjects sometimes initially chose the FR lever, completed one FR 120 run, received reinforcement, then began a FR run that they chose to terminate, and failed to recommence, after as few as 20 to 30 responses. On the next trial, these subjects invariably chose the FI schedule.

FI responding varied from extremely efficient responding of 1 or 2 responses per reinforcement to extremely ineffective 150 responses per reinforcement, a not unsuspected finding, given Weiner's (1962) similar observations of inefficient human responding on FR schedules that do not employ response cost factors, and the lack of an $S^{D}$ to signal reinforcement availability (Goodman, 1970). Notwithstanding the relatively inefficient FI performance of some subjects, and the potentially higher rates of FR reinforcement, the preference for FI schedules over FR schedules predicates an interspecies allure for FI schedules over FR schedules in raccoons and pigeons as well as in man (cf. King et al., 1974; Schaeffer, 1979).

\section{EXPERIMENT 2}

To determine whether reduced FR response requirements might alter the preference for FI over FR schedules, an experiment in which the FI schedule was held constant while FR schedule requirements were varied was conducted. Using the FR 120 value of Experiment 1 as a basic reference point, FR values of $100,80,60$, and 40 were selected for comparisons with the FI 30-sec schedule. Separate and independent 
groups of male and female subjects were assigned to each FR value tested.

\section{Procedure}

Three groups of three male and three female subjects were assigned to the FR 40, 60, and 80 conditions. The FR 100 group consisted of four males and four females. Each group was treated precisely as were the subjects in Experiment 1, as outlined in the General Procedure section above, with the sole exception that the FR requirements among the four groups in Experiment 2 were varied, whereas the FR requirement for the subjects in Experiment 1 was held constant.

\section{Results and Discussion}

Table 1 summarizes the preference data obtained from the four groups in Experiment 2. As in Experiment 1, percent choices to enter a schedule and percent reinforcements earned in that schedule were equivalent. As noted above, schedule selection determined percent reinforcements earned on that schedule, rather than the converse, for the pilot data, and Experiment 1 showed reinforcement rate in the FR 120 was potentially equal to or greater than reinforcement rate for the FI $30-\mathrm{sec}$ schedule; thus, potential rates of reinforcement for the FR 100, 80, 60, and 40 schedules were greater than potential rate of reinforcement for the FI schedule. In spite of this potential favorable difference in reinforcement rate for FR schedules, the FI schedule was preferred by both sexes to the FR 100 and FR 80 schedules. The lower FR response of 60 combined with the increased reinforcement rate was sufficient to induce a FR schedule preference for the females but not for the males. The low FR 40 requirement, combined with the substantial relative increase in rate of FR reinforcement over the FI condition, generated a preference for the FR 40 over the FI 30 -sec schedule for both sexes.

Relative to FR responding in Experiment 1, overshooting of the FR requirements in Experiment 2 was minimal, primarily because Experiment 2 subjects seldom began a FR run that did not terminate in reinforcement, but also because they did respond as inefficiently as the subjects in Experiment 1 . Interestingly, but inexplicably, preference for the FR 60 and FR 40 schedules over the FI $30-\mathrm{sec}$ schedule in all cases was associated with highly ineffective, unnecessary responding on the FI schedule. Whether this correlation was spurious or significant, and whether the causative relation involved ineffective responding producing an alteration in preference, or preference differentially affecting rate of inefficient responding, cannot be ascertained from the present study. Nonetheless, all factors considered, it was clear that neither a decreased FR requirement nor a potential increase in rate of reinforcement was sufficient, in and of itself, to alter the basic preference for FI over FR schedules. However, when rate of reinforcement on the FR was approximately double rate of reinforcement on the FI, and the FR requirement was 60 or less for males and 40 or less for females, the FR was preferred over the FI schedule.

\section{EXPERIMENT 3}

In Experiments 1 and 2, independent groups were used to assess preferences between a FI 30-sec schedule that was compared with FR schedules with response requirements of $120,100,80,60$, and 40 . Given the results presented above, it could be hypothesized that: (1) females ought to prefer FR schedules over a FI 30-sec schedule when the FR schedule requirement is 40 or less and reinforcement rate of the FR is twice that of the FI, and (2) males ought to prefer FR schedules over a FI 30-sec schedule when the FR requirement is 60 or less and reinforcement rate on the FR is at least twice that of the FR. To explore this possibility, Experiment 3 was conducted.

\section{Procedure}

Two groups, each composed of two males and two females, participated in this experiment. One group was initially trained to respond for five consecutive reinforcements each, on a FR 40 and a FI $30-\mathrm{sec}$ schedule, with order of schedule presentation within the group counterbalanced as described above. Following training, the first preference phase was begun. When the subject had earned 15 reinforcements, thereby completing the first preference test phase, the experimenter reentered the room, informed the subject that the FR requirement would be changed, whereas the FI requirement would remain the same, and left the room. After the subject earned an additional 15 reinforcements, the experimenter reentered the room, repeated the above information, then again left the room. This procedure was continued until all subjects in this group received preference testing on the increasing set of FR requirements, which was increased stepwise from 40 , to 60 , to 80 , to 100 responses, in ascending order. As in Experiments 1 and 2, the FI 30 -sec schedule was held constant. Unlike Experiments 1 and 2, which permitted subjects to earn a total of 50 uninterrupted reinforcements on each FR preference test, Experiment 3 restricted subjects to only 15 uninterrupted reinforcements for each FR requirement tested. Since the subjects in Experiment 3 received 15 reinforcements at each FR step, the total number of reinforcement deliveries they received in the preference tests equaled 60 , for a grand possible total of 480 points.

For the second group the procedure was altered to permit initial training of these subjects on the FR 100, then preference testing on a descending series of FR requirements from FR 100, to 80 , to 60 , to 40 . As with the first group, this group earned 15 reinforcements per preference test, and 5 reinforcements each on the FR 100 and FI 30-sec schedules in the training phases. In all respects other than those just described, the general procedure used for Experiments 1 and 2 applied.

\section{Results and Discussion}

As is clear from Table 2, only two generalizations apply to these data: (1) All groups preferred the FR 40 over the FI, and (2) all groups preferred the FI over the FR 100. Additionally, both female groups preferred the FR 60 over the FI. For all other comparisons, a FR reinforcement rate twice that of the FI was not necessary to produce a FR schedule preference. However, in all cases where FR reinforcement rate was at least twice the FI reinforcement rate, the FR schedule was preferred. Obviously, the specific hypotheses from Experiments 1 and 2 that generated Experiment 3 were not confirmed by Experiment 3. 
Table 2

Mean Values of Dependent Variables from the Choice Phases of Experiment 3 for Various FR Schedules and the FI 30-sec Schedule

\begin{tabular}{|c|c|c|c|c|c|c|c|c|c|c|c|c|c|c|c|c|}
\hline & \multicolumn{4}{|c|}{$\begin{array}{c}\text { Percent Schedule } \\
\text { Entries }\end{array}$} & \multicolumn{4}{|c|}{$\begin{array}{l}\text { Percent Reinforcements } \\
\text { Earned Each Schedule }\end{array}$} & \multicolumn{4}{|c|}{$\begin{array}{l}\text { Reinforcement } \\
\text { Rate/Minute }\end{array}$} & \multicolumn{4}{|c|}{$\begin{array}{c}\text { Response } \\
\text { Rate/Minute }\end{array}$} \\
\hline & \multicolumn{2}{|c|}{ Male } & \multicolumn{2}{|c|}{ Female } & \multicolumn{2}{|c|}{ Male } & \multicolumn{2}{|c|}{ Female } & \multicolumn{2}{|c|}{ Male } & \multicolumn{2}{|c|}{ Female } & \multicolumn{2}{|c|}{ Male } & \multicolumn{2}{|c|}{ Female } \\
\hline & D & $\mathbf{A}$ & D & $\mathbf{A}$ & D & $\mathbf{A}$ & D & A & D & $\mathbf{A}$ & D & $\mathbf{A}$ & D & $\mathbf{A}$ & D & $\mathbf{A}$ \\
\hline $\begin{array}{l}\text { FR } 40 \\
\text { FI } 30\end{array}$ & $\begin{array}{r}100 \\
0\end{array}$ & $\begin{array}{l}80 \\
20\end{array}$ & $\begin{array}{l}70 \\
30\end{array}$ & $\begin{array}{l}69 \\
31\end{array}$ & $\begin{array}{r}100 \\
0\end{array}$ & $\begin{array}{l}83 \\
17\end{array}$ & $\begin{array}{l}80 \\
20\end{array}$ & $\begin{array}{l}78 \\
22\end{array}$ & 2.5 & $\begin{array}{l}2.1 \\
1.3\end{array}$ & $\begin{array}{l}3.1 \\
1.0\end{array}$ & $\begin{array}{l}2.5 \\
1.0\end{array}$ & 40 & $\begin{array}{l}42 \\
12\end{array}$ & $\begin{array}{r}41 \\
4\end{array}$ & $\begin{array}{l}40 \\
18\end{array}$ \\
\hline $\begin{array}{l}\text { FR } 60 \\
\text { FI } 30\end{array}$ & $\begin{array}{l}13 \\
87\end{array}$ & $\begin{array}{l}37 \\
63\end{array}$ & $\begin{array}{r}100 \\
0\end{array}$ & $\begin{array}{l}66 \\
34\end{array}$ & $\begin{array}{l}10 \\
90\end{array}$ & $\begin{array}{l}47 \\
53\end{array}$ & $\begin{array}{r}100 \\
0\end{array}$ & $\begin{array}{l}73 \\
27\end{array}$ & $\begin{array}{r}.8 \\
1.0\end{array}$ & $\begin{array}{l}1.6 \\
1.0\end{array}$ & 1.4 & $\begin{array}{r}2.3 \\
.7\end{array}$ & $\begin{array}{l}83 \\
19\end{array}$ & $\begin{array}{l}70 \\
45\end{array}$ & 69 & $\begin{array}{l}61 \\
21\end{array}$ \\
\hline $\begin{array}{l}\text { FR } 80 \\
\text { FI } 30\end{array}$ & $\begin{array}{l}14 \\
86\end{array}$ & $\begin{array}{l}56 \\
44\end{array}$ & $\begin{array}{l}57 \\
43\end{array}$ & $\begin{array}{l}28 \\
72\end{array}$ & $\begin{array}{l}13 \\
87\end{array}$ & $\begin{array}{l}54 \\
46\end{array}$ & $\begin{array}{l}60 \\
40\end{array}$ & $\begin{array}{l}29 \\
71\end{array}$ & $\begin{array}{l}1.0 \\
1.1\end{array}$ & $\begin{array}{l}1.2 \\
1.0\end{array}$ & $\begin{array}{l}2.0 \\
1.0\end{array}$ & $\begin{array}{r}.9 \\
1.3\end{array}$ & $\begin{array}{r}136 \\
21\end{array}$ & $\begin{array}{r}81 \\
3\end{array}$ & $\begin{array}{r}84 \\
3\end{array}$ & $\begin{array}{l}84 \\
26\end{array}$ \\
\hline $\begin{array}{l}\text { FR } 100 \\
\text { FI } 30 \\
\end{array}$ & $\begin{array}{l}37 \\
63 \\
\end{array}$ & $\begin{array}{l}46 \\
54 \\
\end{array}$ & $\begin{array}{l}33 \\
67 \\
\end{array}$ & $\begin{array}{l}18 \\
82 \\
\end{array}$ & $\begin{array}{l}43 \\
57 \\
\end{array}$ & $\begin{array}{l}47 \\
53 \\
\end{array}$ & $\begin{array}{l}43 \\
57 \\
\end{array}$ & $\begin{array}{l}18 \\
82 \\
\end{array}$ & $\begin{array}{l}1.4 \\
1.0 \\
\end{array}$ & $\begin{array}{l}1.3 \\
1.2 \\
\end{array}$ & $\begin{array}{l}1.2 \\
1.6 \\
\end{array}$ & $\begin{array}{r}.8 \\
1.4 \\
\end{array}$ & $\begin{array}{r}123 \\
59 \\
\end{array}$ & $\begin{array}{r}116 \\
22 \\
\end{array}$ & $\begin{array}{r}117 \\
20 \\
\end{array}$ & $\begin{array}{r}100 \\
30 \\
\end{array}$ \\
\hline
\end{tabular}

Note $-D=$ descending order, $A=$ ascending order.

\section{GENERAL DISCUSSION}

Given the data obtained, it appears that FI schedules are generally preferred over FR schedules, even when relative response rates emitted on the FI schedule are not significantly lower than response rates required by the FR schedule, and reinforcement rate on the FR is equal to or greater than that of the FI. Potentially relatively higher FR reinforcement rates do not change subjects' basic FI preferences, especially when FR requirements are high. However, concomitant decreases in FR response requirements and increases in FR reinforcement rates, relative to constant FI response and reinforcement rates, can change a prior FI preference to a FR preference.

The present report emphasized average group data. However, the preference methodology described may be used to assess the hierarchical arrangement and relative positive and negative attributes and effects of stimuli, responses, reinforcement schedules, and motivational states for individual subjects. Thus the present methodology may be used for extended testing of the Premack (1965) reinforcement principle (Schaeffer, 1979). and for prediction and quantification of collateral or adjunctive behavior (Falk, 1969) to be expected of animals exposed to schedules known to produce aggression (Gentry \& Schaeffer, 1969), polydipsic fluid ingestion (Falk, 1969; Schaeffer, 1977), and locomotor activity (Levitsky \& Collier, 1968).

\section{REFERENCES}

FALK, J. L. Conditions producing psychogenic polydipsia in animals. Annals of the New York Academy of Sciences, 1969, 157, 569-593.

Gentry, W. D., \& Schaeffer, R. W. The effects of FR response requirement on aggressive behavior in rats. Psychonomic Science, 1969, 16, 39-41.

Goodman, A. S. The effects of instructions, response cost, and reinforcement availability discriminative stimulus on human operant behavior. Unpublished doctoral dissertation, Florida State University, 1970.

King, G. D., Schaeffer, R. W., \& Pierson, S. C. Reinforcement schedule preference of a raccoon. Bulletin of the Psychonomic Society, 1974, 4, 97-99.

Levitsky, D. A., \& Collier, G. Schedule-induced wheel running. Physiology \& Behavior, 1968, 3, 571-573.

Premack, D. Reinforcement theory. In D. Levine (Ed.), Nebraska symposium on motivation. Lincoln: University of Nebraska Press, 1965.

Schaeffer, R. W. Overshooting of the FR requirement. Psychological Record, 1966, 16, 17-23.

SchaEfFe R, R. W. The response of desalivate rats to a timedependent food reinforcement schedule. Physiology \& Behavior, 1977, 18, 895-899.

Schaeffe R, R. W. Pigeons' preferences for FI over FR food reinforcement schedules. Bulletin of the Psychonomic Society, 1979, 14, 173-176.

WEINER, H. Some effects of response cost upon human operant behavior. Journal of the Experimental Analysis of Behavior, 1962, 5, 201-208.

(Received for publication July 10, 1979.) 